\title{
"Japanese English": A Descriptive Grammar of Concord in the English Written by Educated Japanese
}

\author{
Kolawole Waziri Olagboyega
}

\begin{abstract}
As an attempt to conflate the existing pedagogical concept of "Standard English" and the emerging theoretical notion of "standard non-native varieties of English", this study looks at the stability of the claimed "characteristic" forms of "Japanese English" and shows the statistical likelihood of their occurrence in particular syntactic and semantic environments. This approach is both pedagogically and theoretically interesting inasmuch as it identifies the divergent forms. The classroom teacher, for example, may know what to "correct" and the textbook writers what to highlight. The theoretical linguist who argues for the existence of non-native standard varieties of English has also got ready evidence on which to draw; evidence that can also validate the concept of "fossilization", which seeks to account for the adult non-native speaker's grammatical variability. My starting point was to compile a corpus of the "educated written English" in Japan. The corpus consists of material that appears in the four Japanese national English-language newspapers, Asahi Evening News, Japan Times, Mainichi Daily News, and The Daily Yomiuri which comprises the editorials, articles, advertisements, letters to the editor, etc.; government publications, such as those of the Japanese Ministry of Education, Culture, Sports, Science and Technology (MEXT); articles published in English by Japanese University professors and the writing of university students in Japan. Statistical information is given in the text itself. Because we are interested in the language produced by a people or group of speakers rather than the individual variability within the group, the data-base is cross-sectional rather than longitudinal. We are concerned here with agreement in number between the head of the NP, which is typically a noun, and other elements such as determiners, quantifiers, verbs and numerals. Our data indicates a high percentage of conflicts between the principles underlying concord in the English written by educated Japanese. In numerous examples, there seems to be a conflict between grammatical concord and attraction through proximity. The principle of attraction through proximity here, however, does not seem to be reinforced by notional concord, and that is why these examples may seem divergent. On that basis, we can reasonably conclude that divergence in concord in educated written English in Japan largely reflects the conflict between grammatical concord and concord of proximity, which is not uncommon in this area of standard practice. However, the data seems to also suggest that either there exists something called 'English usage in Japan' or that there exists something called 'Japanese English'.
\end{abstract}

Index Terms-Concord, descriptive grammar, Japanese English, new Englishes.

\section{INTRODUCTION}

This research project represents my ongoing attempt to

Manuscript received January 19, 2019; revised March 19, 2019.

K. W. Olagboyea is with Tsuru University, Department of English, Faculty of Letters and Graduate School, Yamanashi, Japan 402-8555 (e-mail kola@ tsuru.ac.jp). explore non-native varieties of English, which has come to define my experience within teaching and research networks. Arguments rejecting the pedagogic notion of "Standard English" or "correctness", and suggesting that all forms of English are equal, have resulted in the proliferation of terms such as "Indian English", "Singapore English", "Filipino English", "Japanese English" etc., which are claimed to be on precisely the same equal footing with "American English", "British English", "Australian English" [1], [2].

The term "Japanese English" has also gained currency amongst many linguists, anthropologists, sociologists, cognitive scientists and ordinary people both inside and outside of Japan [3]-[7].

However, the most comprehensive study on the subject of "Japanese English" was conducted by Stanlaw [7]. In his seminal study done from "an anthropological linguistic perspective", Stanlaw describes "Japanese English" as "a created-in-Japan variety for use by Japanese in Japan regardless of how they may appear to native English speakers" (p. 299). In other words, the Japanese do not aspire to approximate the native norm. He claims that in the larger context of "world Englishes", "Japanese English" is so entrenched that English has become “... a Japanese language" (p. 300). This is an extreme position which few scholars share with Stanlaw. And, this is not my position.

The tendency among researchers on the subject of English in Japan has largely been to provide glossaries of coinages and other lexical modifications, and the listing of isolated examples of divergence, and present them as "the features" of "Japanese English" [7]. Caught helplessly in this controversy especially in a country such as Japan, where English language is chiefly acquired through formal education, is the classroom teacher, who needs to know what form of English to teach, and which reference books to use.

The focus exclusively on isolated examples of divergence, in the final analysis, does not provide the classroom teacher in Japan with a full knowledge of what needs to be highlighted in the classroom; nor the theoretical or descriptive linguist with what needs to be observed and analyzed.

This study does not select isolated examples of forms to corroborate or falsify any theoretical position or construct, which has been the general trend of research in the field. Instead, it seeks to provide a descriptive grammar of aspects of educated written English in Japan, on which those concerned with teaching English in Japan particularly at junior high, high school and university can draw; it seeks to demonstrate that across the range of forms which are regularly identified as "errors" in the English written by educated Japanese, there are some environments which regularly reflect "Standard English practice" and others 
where "divergent forms" are manifested with some degrees of frequency. The discrimination between the different types of environment gives some idea of the possible reasons for this variation and how to set about correcting it in the classroom.

This study focuses on the realization of concord in "Japanese English". Concord is one area in English which is characterized by competing rules. Each "exception" to the main underlying grammatical principle constitutes another determining principle with the result that there is often variation and uncertainty even in standard practice. Quirk et al [8] for instance observe that:

English speakers are often uncertain about the rules of concord. Prescriptive teaching has insisted rather rigidly on grammatical concord, with the result that people often experience a conflict between this rule and the rule of notional concord, which tends to prevail over it.

In the first section of this chapter, we shall examine the principles underlying concord in standard practice. We shall then, in the following sections, discriminate in educated written English in Japan between environments where concord regularly reflects standard practice, and areas where divergence is manifested.

\section{Scope, DATA AND MethodOlOGY}

As an attempt to conflate the existing pedagogical concept of "Standard English" and the emerging theoretical notion of "standard non-native varieties of English" [9], [10], this study looks at the stability of the claimed "characteristic" forms of "Japanese English" and shows the statistical likelihood of their occurrence in particular syntactic and semantic environments.

This approach is both pedagogically and theoretically interesting inasmuch as it identifies the divergent forms. The classroom teacher, for example, may know what to "correct" and the textbook writers [11] what to highlight. The theoretical linguist who argues for the existence of non-native standard varieties of English [12], [13] has also got ready evidence on which to draw; evidence that can also validate the concept of "fossilization" [14], which seeks to account for the adult non-native speaker's grammatical variability.

My starting point was to compile a corpus of the "educated written English" in Japan. The corpus consists of material that appears in the four Japanese national English-language newspapers, Asahi Evening News, Japan Times, Mainichi Daily News, and The Daily Yomiuri which comprises the editorials, articles, advertisements, letters to the editor, etc.; government publications, such as those of the Japanese Ministry of Education, Culture, Sports, Science and Technology (MEXT); articles published in English by Japanese University professors and the writings of university students in Japan. Statistical information is given in the text itself. Because we are interested in the language produced by a people or group of speakers rather than the individual variability within the group, the database is cross-sectional rather than longitudinal.

The newspapers have been selected for this study for several reasons. Published daily (Monday to Sunday), they are the most widely circulated national English-language newspapers in Japan. Even though English newspapers in Japan have a very limited number of subscribers, they are read by those whose proficiency in English ranges from the lowest to the highest (native-like). The newspapers constitute what might be called the Japanese quality press.

It should be noted that even though most of the four English language newspapers used for this study most likely have native speaker grammar checkers who work there full time, there was a very limited "contamination" on the data collected. Diligent efforts were made to specifically select various articles written by the same Japanese writers, which have shown consistent divergent tendencies. It is therefore possible to assume that those articles were either not checked or that the grammar checkers were unconscious of the consistency with which the divergent forms occur in those articles.

The corpus also includes data collected from the articles published in English by Japanese university professors, and data collected from MEXT publications. These and the English of Japanese newspapers are what we are associating with "educated English" (call it the "acrolectal") in this study. These are the highest levels at which we are readily able to find a corpus from the daily communicative experience of the people, large enough to be well representative of the major forms, and quite convenient for detailed examination. Other bases, such as students' writing collected at various levels, will show tendencies that are generally associated with early and middle learners (the "basilect" and the "mesolect" speakers). It is necessary to emphasize tendencies in relation to a database because there seems to be no objective way of dividing the cline of bilingualism. In sociolinguistic terms [15]-[17], the levels of proficiency are grouped into those broad stages of the acquisition process, each of which is associated with a variety of the language.

The data for this study was collected manually and was therefore very laborious. Each detected divergent form is then manually fed into the Word document, which serves as the computerized "tool" and corpus for the study.

As we are interested in the description of data rather than the explanation of a theory or process, the approach is more inductive than deductive. The realization of the grammatical categories that are typically associated with the concord, are examined in the English of the newspapers, in the writings of university professors, the government publications and the writings of university students. The environments where persistent patterns and tendencies emerge are described and tabulated with a view to determining the extent to which the patterns may be said to represent stabilized usage based on a specifically Japanese syntax and semantics as opposed to (American) Standard English practice.

In the discrimination between different types of syntactic environment, our pedagogical aims will take precedence, and we shall be suggesting one grammatical approach or another. The main purpose, however, is not to prescribe any particular approach but to furnish the teacher-trainer, textbook writer and curriculum designer with an eclectic mixture of methodological frameworks which will be useful in approaching a particular problem.

The relations between the standard forms and the divergent forms, and their percentages of co-occurrence will provide 
helpful insights into various theoretical issues. For example, the corpus shows no grammatical categories that regularly occur divergently only and never standardly. If we accept the general view that there is a distinctive Japanese English usage that can be clearly distinguished from standard practice, then we must allow for a great deal of overlap between "Japanese English usage" and standard practice in the language produced by educated Japanese.

\section{RESUlTS AND DisCUSSION}

\section{A. The Principles that Underlie the Notion of Concord}

In grammatical theory and description, the formal relationship between elements, whereby a form of one constituent requires a corresponding form of another is referred to as concord [18]. We are concerned here with agreement in number between the head of the NP, which is typically a noun, and other elements such as determiners, quantifiers, verbs and numerals. The main principle which determines concord in standard practice is the principle of grammatical concord. There are occasions, however, when the grammar allows for a breach of this "basic" rule. Some writers [19] treat such cases simply as "exceptions to the basic agreement rule". Others [8] consider them as "other principles" of concord. Quirk et al [8] identify two such principles: the principle of notional concord and the principle of proximity. To these we shall add the principle of "gender-neutrality".

\section{1) The principle of grammatical concord}

The rule that the verb matches its subject in number may be called the principle of grammatical concord - i.e., if the subject of the verb is plural, then the verb ought to be plural; and if the subject is singular, then the verb has to be singular. It is also called the "third person rule" [18]. In the most straightforward cases, we may have examples such as:

The men have come / The man has come

They are dying of starvation / He is dying ...

Cows chew grass / A cow chews grass

According to this rule, therefore, the following sentences will be ungrammatical (or grammatical "discord"):

*My brothers lives in Nigeria

*My sister also live in Nigeria

It may be noted that whereas the -s inflection marks plural in nouns (e.g., cow-cows; brother-brothers) it marks singular in verbs (e.g., chew-chews; live-lives). We may note further that not every verb-form (e.g., the modals) exhibits subject-verb agreement [20].

\section{2) The principle of notional concord}

Notional concord, according to Quirk et al [8]: "is agreement of verb with subject according to the notion of number rather than the actual presence of the grammatical marker for that notion". This mainly involves: (i) collectives or collective nouns; (ii) expression of quantity or measure; and (iii) proper names.

i. Collectives

Singular collective nouns (e.g., committee, government, family, staff), which denote a set or collection of separate members, may occur with either the singular form or the plural form of the verb according to whether the notion of number is singular or plural - i.e., whether the focus is on the individual members (plural) of the set or on the set as a unit (singular), e.g.: "The committee has/have accepted the proposal (i.e., "The committee as a body has ... or the individual members have ...").

We may note one or two restrictions here. As we have said, the choice in the form of the verb indicates a choice of focus offered by the predicate. It will follow, therefore, that there will be no choice in the form of the verb if the predicate can be normally understood as offering no choice of focus. For example, in the sentence The Staff consists of one professor and two doctors, the predicate necessarily applies to the set as a whole, eliminating the choice of focus on the members separately. Thus, we may not have: *The staff consist of one professor and two doctors. On the other hand, the plural form of the verb will be more likely in a sentence such as: The staff were enjoying the seminar, since it can be understood as directing attention at the individual reactions of the members of the staff.

Another restriction may lie in the choice of a pronoun. It would appear that the pronoun would agree in number with the singular or plural meaning of the verb. For example, in a sentence such as The government have broken all their election pledges, the plural notion is indicated not only by the form of the verb (have broken), but also by the form of the pronoun (their). So that there may be a contradiction in concord in a sentence such as The government has broken all their election pledges or The government have broken all its election pledges, where the form of the verb seems to signal one notion of number and the form of the pronoun a different notion of number.

It is generally observed [8], [19] that singular collective nouns are usually treated as notionally plural in British English while it is the other way round in American English. It may also be noted that the plural notion of singular collective nouns is common in speech. In the restricted confinements of the classroom and of writing in general the basic rule of agreement is probably preferred. The safe thing to do when in doubt, especially when writing, will be to obey grammatical concord.

Notional concord involving collective nouns is related to the phenomenon of collectivizing. A noun that is grammatically singular can breach the grammatical rule of concord and select a plural verb instead of a singular verb, e.g.: The mob have been throwing stones all day. The phenomenon of collectivizing similarly breaches grammatical concord, and a noun can select its singular form instead of its plural form, e.g.: The poachers shot two elephants yesterday. It could be argued that both cases involve the principle of notional concord. It may be noted, however, that whereas the breach of grammatical concord with regard to collective nouns semantically focuses on the individual members of the group, the breach of grammatical concord with regard to the notion of collectivizing has the opposite semantic effect - i.e.., it treats the separate items as a set. In other words, whereas the grammatical "discord" in the case of one involves a plural notion, it involves a singular notion in the case of the other.

Notional concord involving collective nouns is further related to two types of constructions: (i) as in The board of examiners have called for the examination scripts; and (ii) as 
in A lot of the oranges have gone bad. In the first type of construction, the head of the subject NP (board) is singular, and grammatical concord would thus require the singular form of the verb. So that we can have: The board of examiners has .... But the postmodification of the grammatical head contains a noun (examiners) which, in terms of proximity, is closer to the verb than the grammatical head, which can be any distance away. The plural verb in a construction such as The board of examiners have..., therefore, can be seen as reflecting either notional concord (i.e., with reference to the collective subject NP head board) or the force of attraction through proximity (i.e.., with reference to the noun in the postmodification examiners) each of which reinforces the other. We shall develop this latter point further in the following subsection.

In the second type of construction, we are faced with the issue of identifying the head of the subject NP. In an expression such as a lot of oranges, is the head lot or oranges? It can be either depending on the type of analysis [19]. If we see lot as the head, we can then describe the NP as consisting of Determiner (a), Head (lot) and Complement (of oranges). We can further analyze the complement as a prepositional phrase consisting of head (of) and an NP complement (oranges). Oranges according to this analysis, therefore, is the head of an embedded NP and not the superordinate NP. We may represent it in a tree diagram as figure 1 below:

This structure may also apply to NPs such as a comedy of errors, a collection of antiques, an interest in teaching, where the heads are clearly comedy, collection and interest, and the number of students, where number is indisputably the head. It may be noted, however, that whereas the grammatical number of the NP a lot of oranges depends on oranges, which, according to the above analysis is not its head, in a comedy of errors, for example, the number depends on comedy, which, as we have said, is clearly its head. This analysis of an NP such as a lot of oranges will make it necessary to allow that the syntactic number of an NP may not be determined by its head. An NP such as a lot of oranges is described as being "number-transparent" [19] allowing the number of the NP in the complement to determine the number of the whole (superordinate) NP.

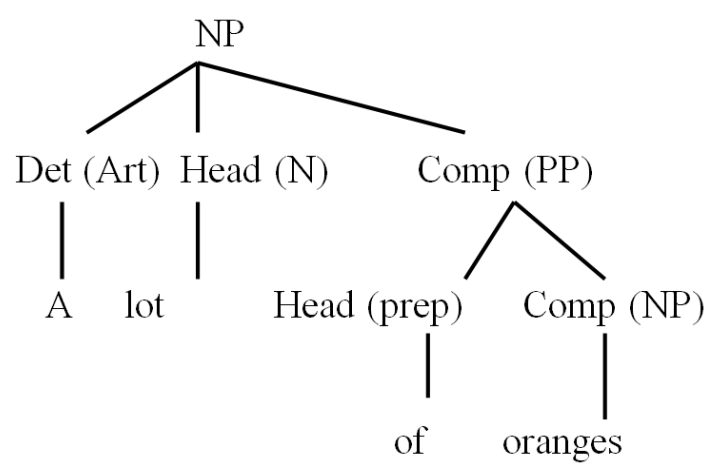

Fig. 1. Tree diagram for "A lot of oranges".

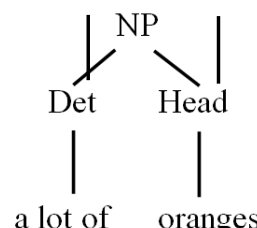

Fig. 2. Tree diagram for "A lot of oranges"
Perhaps in line with the view that an NP's number is determined by its head, oranges can be seen as the head of the NP a lot of oranges. In that case, the NP consists of Determiner (a lot of) and Head (oranges) as in figure 2 above.

We may relate this structure to NPs like several oranges, a dozen oranges, etc. In this case, we shall simply say that a lot of is a determiner and we will not analyze it any further. The attraction of this analysis is that it makes oranges, which determines the number of the NP, the head of the NP. This will be convenient for our classroom purposes, since we can consistently depend on the grammatical number of the NP:

a lot of oranges is a plural NP because its head is plural

a lot of milk is singular because its head is singular

a diet of vegetables is singular since its head is singular

a diet of milk is singular because its head is singular

In terms of position, we shall describe the head of an NP as the first noun after a determiner. So that in the examples above, diet is the first noun after the determiner a, and oranges and milk are the first nouns after the determiner a lot of.

ii. Expression of quantity or measure

Notional concord also occurs where a plural NP can be viewed as referring to a single unit of quantity or measure, such as the rate at which something is done or an amount of something:

a. Two goals in five minutes is not good enough

b. Sixty minutes is too long for the exercise

c. Two pounds of flour was all we needed

The plural subject NPs in these examples can be interpreted in a singular sense. Two goals in five minutes can be interpreted as "that rate of scoring", and the sentence can thus be paraphrased as That rate of scoring is not good enough. Similarly, the NP sixty minutes can be interpreted as "that amount of time" or "the time", and the NP two pounds of flour as "that quantity" or "that amount of flour". The question would then arise as to whether we have the option of using plural verbs, as the subject NPs are plural. The answer cannot be simply yes or no, or rather it can only be yes or no depending on the particular case or context and the speaker. The plural verb would seem a good deal better in example (c) Two pounds of flour were all we needed than in example (b). It would appear from an expression such as (b) above that the "breach of agreement", sometimes, is the more usual thing to do.

iii. Proper names

A plural NP may serve as the name of a single entity, say, the title of a book, poem or play. The semantic predicate will then be predicated of something singular, which will thus require the singular form of the verb:

a. Gulliver's Travels is a satire

b. Bats is her favorite poem

c. The Three Musketeers is an interesting novel

In these examples, the semantic predicates "be a satire", "be her favorite poem" and "be an interesting novel" are predicated of singular subjects - a novel or fiction, a poem and a novel respectively. This accounts for the singular form of the verb "to be" (is). It may be noted, however, that we can interpret the NP Gulliver's travels for example, as the separate journeys described in the novel - i.e., the visits to Lilliput, Brobdingnag, etc. - each of which is described in the style of satire. In this sense it will be possible to say: 
d. Gulliver's travels ["the journeys Gulliver made"] are satires

In expression (a) the subject NP Gulliver's Travels is a proper name. It may be noted that Travel here requires an initial capital letter. In (d) the subject NP consists of a possessive determiner and head (Gulliver's travels). Travel here may not be capitalized.

Where a proper name is a collective noun, notional concord may apply as in the case of singular collective nouns (cf. subsection (i) above). For example, The United Nations is a plural NP but names a single body. It may therefore take a third person singular verb: The United Nations is meeting on the issue now. For the same reason, we may have: The United States is arranging for the peace talks. Since names of countries can be used as collective nouns, and collective nouns permit a plural interpretation, names of countries can occur with a plural verb, for example, when applied to sporting teams representing the country: Japan have reached the quarter-final.

\section{3) Concord of proximity}

Concord of proximity or attraction, often described as "attraction through proximity" [8] occurs when the verb agrees with the number of a closely preceding noun rather than with the head of the subject NP (we take the position that the NP's grammatical number is determined by the number of its head, cf. subsection (i) above). This is particularly the case when the head of the subject NP, through lengthy postmodification or parenthesis, is some distance away from the verb. In the sentence: The board of examiners have called for the examination scripts the plural verb have agrees with the immediately preceding plural noun examiners although the subject NP the board of examiners is grammatically singular, since its head board is singular. On the other hand, the concord of proximity is here reinforced by notional concord, since board, as a collective noun, can be notionally plural (cf. 3.1.2). In a sentence such as: No one except his party members agree with him the plural verb agree agrees with the immediately preceding plural noun members although the subject NP no-one except his party members is grammatically singular, since its head (no-one) is singular. But again, the proximity principle is here reinforced by notional concord ("only his party members agree with him").

Preceding coordinated NPs may also take a plural verb as a result of notional concord, even if they are grammatically singular:

A good knowledge of typing, word processing, and shorthand are required for the job.

\section{4) The principle of gender-neutrality concord}

Another principle closely related to notional concord, and which influences the choice of verbs and pronouns contrary to grammatical concord, is the notion of "gender-neutrality". The use of lexical items which have a masculine connotation for generic or indefinite reference is becoming increasingly unpopular.

In the Sunday Times [21], it was reported that Radio New Zealand has banned 151 "sexist" words, including manhole, snowman, bridesmaid and masterpiece. Even girl, boy, man and wife are in the list. Following this ban, broadcasters have been instructed, for example, to say: Any listener can have their say on radio talkback instead of Any listener can have his say on radio talkback. It is an example like this that we are particularly concerned with here. Obviously, it breaks the rule of grammatical number agreement in preference to what may be called notional concord. We may agree that grammatically the NP any listener is singular, and therefore the pronoun which refers to it should also be singular for them to agree in number. Until now, this analysis will then require the pronoun to be his, which is considered to be indefinite or generic in this context, and which is found to be "normal". This is what is now being described as "sexist", "offensive" and "unscientific" language, and to avoid it, the plural pronoun is preferred in the context, since it is gender-neutral. Since gender differentiation involves the distinctions or terms "masculine" and "feminine", the gender-neutrality principle involves notional plural, as it seeks to combine more than one notion of sexuality. By this reasoning the referent of the NP any listener, in the above example (i.e., both masculine and feminine), is notionally plural, and that justifies the choice of the plural pronoun their.

When the gender-neutrality principles combines with the principle of proximity in a sentence which involves the verb to be or to have and a pronoun, the situation can be quite chaotic. For instance, there is a sense in which each of the following examples can be justified:

(a) Every student have their favorite lecturer.

(b) Every student has their favorite lecturer.

It could be argued that (a) is almost like the example we have just analyzed. That involves mainly the gender-neutrality principle, but (b) combines the principles of gender-neutrality, grammatical concord and proximity. The argument for (b) could be that: every student is grammatically singular and, therefore, requires the singular verb has, but it cannot take a singular pronoun (i.e., his) either because of the gender-neutrality principle or because the third person personal singular pronouns (i.e., he and she) have been banned (cf. the New Zealand case above).

On the other hand, perhaps, it may be argued that there ought to be a consistent choice between the gender-neutrality principle and grammatical concord, so that instead of (b) above it might be preferable to say something like: Every student has his/her favorite lecturer. First, as we have said, this will depend on which pronouns we are left with after the ban. Secondly, such strategies (e.g., s/he, wo/man, etc.) seem convenient only in writing. Despite all the neutral strategies, the possibility of a conflict between the principles underlying concord occurring in a sentence, especially where the sentence is lengthy and includes coordination, parenthesis, etc., is real indeed [8].

Furthermore, we may note some general respects in which the application of the general subject-verb concord rule is restricted. First, except for the verb BE, the verb shows a distinction of number only in the $3^{\text {rd }}$ person present. Hence, the verb generally does not show concord in the past:

My supervisor gave me attention without stint

My supervisors gave me attention without stint The verb Be displays concord also in the $3^{\text {rd }}$ person past:

Jon was helping me on the computer

Jon and Charlotte were helping me on the computer

Secondly, number concord is displayed only in the indicative. Nonfinite verbs, imperatives, and subjunctives 
make no number distinctions:

Jon may help me to print my work

Jon and Charlotte may help me to print my work

With regard to concord in English written by educated Japanese, we may examine three general environments: (1) environments in which grammatical concord is always obeyed; (2) cases which frequently violate grammatical concord but might be justified by the other principles of concord (notional, proximity and gender-neutrality); and (3) environments where only the proximity principle appears to be followed in defiance of the other principles.

\section{B. Environments in Which Grammatical Concord is Always Obeyed in the English Written by Educated Japanese}

There are environments in which educated Japanese, in obedience to the rule of grammatical concord, regularly use a singular verb with a singular subject, and a plural verb with a plural subject.

i. Singular verbs are regularly used with singular subjects when such subjects consist of:

a. singular count NP heads:

1. A special task force has been set up to coordinate and monitor relief operations for victims of the Fukushima earthquake disaster ....

2. A medical officer at the General Hospital denies the allegations ....

3. The report was received by the Prefectural Governor ....

4. The secretary ... explained how the workshop is to be constructed ....

5. Complaining about the high cost of living ..., the speaker noted that a liter of petrol now sells for more than $¥ 100$.

b. noncount NP heads

1. The manager explained to the workers that advertising brings profit in the long run ....

2. Speaking on culture ..., X noted that music plays a vital role in social development ....

3. This evidence, according to the committee, is untenable

4. In his closing remarks, the chairman noted that water is precious, and he called on the community to use it wisely.

5. In his report $\ldots, X$ said that sand was their major problem ....

c. proper nouns

1. Mr. Shinzo Abe, the Prime Minister and chairman of the Committee, has reminded the Japanese that the prefectural assemblies are democratic instruments ....

2. Hurricane "Florence", the most powerful storm to hit the Carolinas in more than a decade, was bearing down on a string of resort islands yesterday ....

3. The White Volta is in flood, and many of the people who live along its banks are abandoning their homes.

4. Japan hosts the forthcoming Asia-Pacific conference ....

5. September always brings sorrow to the inhabitants of the area ....

ii. Finite and nonfinite clauses are regularly marked as singular:

1. Outlining the reasons for their strike action, the secretary noted that how they got their water does not concern the government ....
2. He also remarked that to treat the farmers as illegal immigrants is criminal.

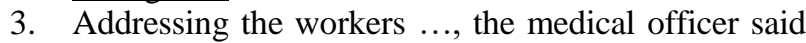
eating vegetables is good for their health.

iii. A plural verb is regularly used with a plural subject. This occurs normally with plural count nouns:

1. ... more than 100 more houses have collapsed since last Thursday when one of the heaviest rains this season was recorded.

2. Some of the low-cost bungalows in the area have also been affected.

3. The farmers ... watch helplessly as their farms are destroyed ....

4. The units of the Ministry which were attacked ... include the Prefectural Medical Stores, the Administration unit and the Environmental Health Department.

5. Receiving the report, $X$ noted that taxi drivers play a very important role in the economy.

6. These dreams, the Leaders of the Revolution observed, these normal human aspirations to which all your people have the right, were violently shattered by the irresponsibility of the past leadership.

\section{Cases Which Frequently Violate Grammatical}

Concord but Which Might be Justified by the Other

Principles of Concord (Notional, Proximity and Gender-Neutrality)

There are three general areas where concord is not straightforward: where the subject contains (1) a collective noun head; (2) coordination; and (3) an indefinite expression.

1) Collective nouns and concord

We shall look at (a) singular collective nouns, and (b) plural collective nouns.

a. singular collective nouns

In strict obedience to grammatical concord, singular collective nouns ought to take singular verbs. However, educated Japanese use either singular or plural verbs with such nouns:

1. In his closing remarks, $X$ noted that the public are tired of demonstrations.

2. Urawa Reds have won the cup ....

3. ... the staff of the corporation are providing labor for the work which is expected to be completed in two weeks' time.

4. The administration has announced its plans for stimulating the economy.

5. The public has a right to know.

6. The NIC sub-committee on timber requests the following contractors to report at the NIC Information Centre ....

7. The Council denies allegations that they are apathetic to development ....

8. Management was divided on the issue.

There is a preponderance of the use of a singular verb with a singular collective noun - 213 out of $287(74 \%)$ cases. It may be noted, however, that the tendency to use both a singular verb and a plural verb with the same singular collective nouns is Standard English practice. The choice depends on whether the group is being considered as a single undivided body, or as a collection of individuals (cf. 3.1.2.i).

In addition to the issue of choice between singular or plural verbs, singular collective nouns also raise the issue of choice between singular or plural anaphoric pronouns. As with the verbs, educated Japanese again use both singular and plural 
pronouns with singular collective nouns. The plural pronoun may be used even when the verb is singular:

1. The committee has not yet decided how they should react to the Minister's letter.

2. The Akita Prefectural Assembly is identifying areas in which it can encourage individuals or groups of persons to establish industries ... in the Prefecture. They observe that there are a lot of resources in the Prefecture which need to be developed for the benefit of the people.

3. The jury which is expected to submit its report by 2 October, include .... In the picture (second from right) is $\mathrm{X}$ briefing the jury on what is expected of them ...

4. The public has again shown their keen interest in the future Government of Japan.

5. It is, therefore, up to Urawa Reds to prove to its admirers and other critics that they are ready for Kashima Anthrax.

Again, it may be noted that the use of plural pronouns to refer to singular collective nouns often occurs in both British and American English [8]:

The committee has not yet decided how they should react to the Governor's letter.

One may think of two things happening here. First, collective nouns such as committee, public, audience, crowd, etc., consist of human beings. The use of the plural pronoun to refer to them, therefore, appears to be a process of avoiding the strong inanimate and nonpersonal connotation of the singular pronoun it, something which is absent in the verb. Secondly, these nouns, as we saw earlier (cf. 3.1.2), offer the choice of their being regarded either as singular or plural, so that there could be some kind of "notional switch" in focus occurring in the course of the sentence or discourse.

b. plural collective nouns

If the collective nouns occur in the plural, the verb is regularly plural:

1. The various assemblies are now meeting to discuss the government's proposal.

2. The various contingents were met by X ....

3. Addressing the people, $X$ noted that local councils are in charge of repairing roads ....

4. He also said that all the committees submit their reports tomorrow ....

2) Coordination and concord

We shall consider three types of coordinate subjects: (a) coordination with and; (b) quasi-coordination; and (c) coordination with or and nor.

a. Coordination with and

Educated Japanese have a tendency to treat every and-coordinated subject as plural. No problem of concord arises in this regard if the subject so coordinated is a full coordinate form. It takes a plural verb whether the conjoins are singular or plural:

1. The governor and people of Akita have celebrated their annual festival ....

2. The granting of loans and measures to ensure regular repayment are the main issues to be discussed.

3. A classroom block and old market have been rehabilitated by the people of Kobe ...

4. A farmer and a fisherman were arrested yesterday ....

5. Nigeria and China have signed a contract ....

A plural verb is similarly used in asyndetic coordination (i.e., without a coordinator):
1. His car, his television, his money were confiscated by the customs officials.

2. His farm, his house were destroyed by the fire.

3. Her hair, her fingernails are her main concerns.

4. A source of good drinking water, a clinic, a good road have always been the demands ....

A problem of concord arises if an and-coordinated subject consists of coordinative apposition - i.e., the noun phrases (or clauses) refer to one entity. A subject so coordinated could have either a singular verb or a plural verb depending on the meaning, thus resulting in a clash between grammatical concord and notional concord. In the following examples, although the subjects are considered as plural perhaps because of the coordination, there is a sense in which they may require singular verbs despite the coordination:

1. The cocoa tree, drum and open book were flying from the flagpole.

Note that this is a figurative (metonymic) expression. The cocoa tree, drum and open book are the symbols in the flag and are, therefore, made to stand for the flag. They can thus be taken together as the flag, and be given a singular verb (cf. "the skull and crossbones was flying from the mast head")!

2. Gari and beans make a good solid Nigerian breakfast.

The subject Gari and beans actually names a single meal which in a Nigerian language is called "Sokudale". In this sense, it may require a singular verb. (cf. "Bacon and eggs makes ....)

3. The Husbands and Wives only admit adults.

The subject names a single pub, and may therefore require a singular verb.

4. The referee's fairness and impartiality have been much appreciated.

5. The goalkeeper's calmness and confidence are astonishing.

6. Law and order have been established in X ... which has experienced series of chieftaincy disputes during the past few months.

In the last three examples, 4-6, the use of the plural verbs suggests that the subjects are considered as consisting of separate qualities. However, if qualities are seen as a complex unity, then singular verbs might be required:

7. The chief's aged spokesman and the caretaker of the palace were with him at his deathbed.

By using a plural verb, the writer means or implies that the chief's spokesman and the caretaker of the palace are two different people. But they could also be the same person, in which case the singular was would be required.

b. Quasi-coordination

Another type of coordination which causes concord problems for educated Japanese is quasi-coordination - i.e., prepositions (such as along with, rather than, as well as) which are semantically similar to coordinators - are sometimes treated as plural - 21 out of $348(6 \%)$ examples manifested this tendency. In the following examples, grammatical concord requires a singular verb. The plural verb appears to be prompted by the principle of notional concord (sometimes combined with the proximity principle):

1. The secretary, as well as the other workers, were tired.

2. One speaker after another were complaining about the government's apparent neglect of the rural areas.

3. One man with his wife, both arriving from farm and looking very dirty, were willing to attend the meeting. 
4. The Prefectural Governor, together with his advisers, are preparing a statement on the land disputes in the prefecture.

5. A teacher, and sometimes a farmer, are often invited to address the organization....

c. Coordination with or and nor

When subject phrases or clauses are coordinate with or and nor grammatical concord is clear if each member of the coordination has the same number: when they are both singular, the verb is singular; when they are both plural, the verb is plural:

1. Either the Prefectural Governor or his deputy is bound to come.

2. Either the strikers or the bosses have misunderstood the claim

3. Neither he nor his wife has arrived.

4. Neither the workers nor the government representatives were prepared for a compromise.

5. The teachers or the students are to be held responsible.

A problem arises when one member is singular and the other plural. Or is notionally disjunctive, making each member relate separately to the verb rather than combining the two members as a unit, for example, as when the coordination consists of additive and. Since the members are separately related to the verb, we cannot say, either by the principle of grammatical concord or notional concord, that the subject NP is singular or plural. Proximity is the determinant principle: whichever phrase comes last (i.e., nearest to the verb) determines the number of the verb. The divergent tendency in Japanese newspapers is to use a plural verb once one of the members is plural. In 360 examples where the first member is plural and the second member singular (pl. + sing.), and proximity would thus require a singular verb in standard practice, proximity is overruled by plural in 14 (or $4 \%$ of) cases:

1. Either the driver's brakes or his eyesight are at fault.

2. The students or the teacher are to be blamed ....

3. Neither the people nor governor were pleased with the proposal ....

4. Either the women or the boy were lying ....

5. Neither the women nor their husband were invited ....

The coordinating correlatives not...but and not only/just/merely...but (also/even) behave like or with respect to number concord in standard practice. Number agreement is clear if each member of the coordination is of the same number: when they are both singular, the verb is singular; when they are both plural, the verb is plural. This is regularly the case in Japanese newspapers:

7. Not only the Prefectural Governor but the Gakucho has arrived.

8. Not just the farmers but also the fishermen were invited.

Divergence occurs in Japanese newspapers where the members of the coordination differ in number. Standard practice would generally have recourse to proximity in such a case. Proximity is sometimes overruled by plural in Japanese newspapers. In 220 examples where the first member is plural and the second member singular (pl. + sing.) proximity is overruled in 7 (3\% of) cases:

9. Not only the farmers but also the workers were summoned ....

10. Not just the market women but their spokesperson were arrested.

\section{3) Indefinite expressions as subject}

We are interested here in subjects which consist of indefinite expressions of amount or quantity, especially with the determiners and with the pronouns no, none, all, some, any, and fractions such as half. They have both count and noncount uses. We may identify three environments of these expressions with regard to subject-verb concord: (a) with noncount nouns; (b) with plural count nouns; and (c) none with plural count nouns.

a. with noncount nouns

In general, subject-verb agreement where the head of the subject NP is a noncount noun, like number realization involving noncount nouns, is not a straightforward case in English written by educated Japanese. Much depends on the particular noun involved. Indefinite expressions of amount or quantity involving some noncount nouns in Japanese newspapers, as in standard practice, regularly use singular verbs:

1. So far, no money has been spent on repairs.

2. Some cement has arrived.

3. All the stone was used ....

4. None of the sand has been brought, and the workers are complaining ....

5. Half the gravel was left at the roadside.

But we see divergent examples such as:

a. *Furnitures are being manufactured in Akita.

b. *The luggages were burnt.

As we explained, we would like to see these examples as reflecting morphological issues involving number realization rather than syntactic issues of number agreement (or concord). If we agree that the divergent (heads of the) subject NPs *furnitures and *luggages express the plural notion, then grammatical concord will require that they occur with plural verbs as indeed will be the case with their standard equivalents pieces/items of furniture, items of luggage:

c. Articles of furniture are being manufactured ....

d. The items of luggage were burnt

The difference between examples (a) and (b), on the one hand, and (c and (d), on the other hand, lies in the realization of the plural notion of number involving the noncount nouns furniture and luggage. Thus, we would consider the divergence reflected in examples (a) and (b) as morphological rather than syntactic. It may be interesting to note, however, that we also found examples such as:

e. *The equipment were received ....

f. *All traffic ... should divert their course .... which we said involve issues of concord or syntax (cf. 2.1.2.4). The point about these examples, unlike (a) and (b), as we discussed, is that they involve both morphological and syntactic issues. Obviously, they raise no overt morphological question of divergence. But the form of the verb or other elements in the sentence, such as anaphoric pronouns and quantifiers, would suggest that the subject NP is being considered as plural. We may thus infer that the heads of such NPs (e.g., traffic, equipment, etc.) are being equated with nouns, such as sheep, aircraft, cattle, etc., that do mark for plural (but may occur with plural verbs). In this sense, the divergence in examples (e) and (f) can be seen not simply as a matter of concord but as being basically related to the whole complex issue of number realization involving noncount nouns. We can thus assert that any grammatical "discord" in Japanese newspapers where the head of the 
subject NP is a noncount noun will generally relate to the morphological issue of number realization.

We have taken the position, for the convenience of a systematic classroom analysis of divergence involving the categories of number and concord, that the subject NP governs concord, and that (cf. 3.1.2) the grammatical number of the NP is determined by the grammatical number of the head of the NP. In this connection, we shall suggest two ways of correcting a divergent form such as (f) above in the classroom. One, the antecedent traffic could be replaced with an item (plural in number) such as cars or vehicles to agree in number with the anaphoric pronoun their. On the other hand, the plural their could be replaced with its singular form its to agree with the singular (noncount) head of the subject NP traffic.

It is particularly interesting to note that replacing the form traffic with a form such as cars or vehicles would result in grammatical concord. It supports our assertion that any grammatical "discord" in Japanese newspapers where the head of the subject NP is a noncount noun will generally relate to the morphological issue of number realization. If we take the word traffic to mean "all the cars, buses, trucks, and other vehicles that are moving along a road at any one time" [22], then in our classification of nouns that are often involved in divergent tendencies in the English of educated Japanese, traffic will fall in the class of noncount nouns that consist of several different countable nouns.

b. with plural count nouns

With plural count nouns, plural verbs are regularly used:

1. Some tables have been bought for the school.

2. Half of the chairs in the school are broken.

3. All parents have been asked to contribute towards the development of the school.

4. Some of the teachers are not happy about the proposal.

5. Hardly any of the government's proposals ... were pleasing to the Parent-Teachers Association.

c. none with plural count nouns

The use of none with plural count nouns is another environment where concord does not present a straightforward case in standard practice. It is in divided usage, accepting both the singular and the plural forms of the verb [8]. The use of the singular verb in such contexts appears to be on the insistence on prescriptive practice, but notional concord (often reinforced by proximity) may suggest the plural verb, which, according to Quirk et al [8], is frequently used and is generally accepted in Standard British English. The use of the singular verb is the general practice in Japanese newspapers. But there is also a tendency to use the plural verb in such contexts. In 280 examples which would accept either a plural verb or a singular verb, the plural verb was used in $12(4 \%)$ cases:

1. None of the books have been taken away .... .

2. None of the students were there to listen to the speaker... .

3. None of the parents have come to watch the play ....

4. Although the association has written several letters ... none have been answered ....

5. The Prefectural Governor was happy to note that none of the farmers in the Prefecture are complaining about the equipment supplied by the Ministry of Agriculture ....

With reference to the indefinite pronouns (everyone, everybody, someone, anyone, anybody, no one, nobody) we saw, in discussing the gender-neutrality principle (cf. 3.1.4), that it has now become standard practice to use the $3^{\text {rd }}$ person plural. It is a convenient means of avoiding the dilemma of whether to use the he or she form:

Has everyone paid their consumption tax?

No-one has brought their keys, and everyone had to wait their turn to use the master key.

The indefinite pronoun one is not in conflict in standard practice with the gender-neutrality principle, since it is followed by the same pronoun for subsequent references:

One should choose one's financial advisers carefully.

One has been asked to do a Nescafe commercial because one has taste.

One should use one's vote wisely.

There is a tendency on the part of educated Japanese, as in American English, to use the he form. In 320 examples which have the indefinite pronoun one as the subject, the he form occurred in $16(5 \%)$ cases:

One does not know his left from his right.

One has just taken over the administration ... and does not know whether he is going or coming.

One must know his rights and must not allow himself to be cheated ....

This use of the he form to subsume both masculine and feminine references, as we have said, is increasingly becoming unpopular, and one of the lines along which we can expect to find a diachronic change in the English of Japanese newspapers is the replacement of indefinite one with indefinite we, you, or they, as the case may be:

We should choose our friends carefully (instead of "one should choose one's friends carefully")

You should use your vote wisely (instead of "one should use one's vote wisely").

Those who want to rule must first learn to obey (instead of "he who wants to rule must first learn to obey").

\section{Environments which seem to reflect only the proximity principle in defiance of the other principles of concord}

There are cases of concord, in English written by educated Japanese, which seem to reflect only the proximity principle in defiance of the other principles of concord. Judgement here is likely to be subjective. But the classroom teacher applying strict considerations of grammatical concord would normally condemn such cases as errors. We may broadly identify two such areas: (a) environments in which the difficulty may be attributed to premodification; and (b) cases where the choice of the verb seems to be influenced only by an immediately preceding noun.

a. premodification

There is a tendency to mark a countable noun for plural if it combines with a numeral to form a premodification which expresses precise measure, quantity, etc. In 418 examples where a count noun combines with a numeral to form a plural premodification, the noun is marked for plural in $20(5 \%)$ cases:

1. This was at a service held to mark the end of the three days period of national meditation ....

2. The four-engines DC Plane apparently was bound from Venezuela for the region of Detroit.

3. The roofs of 27 buildings including two Secondary Schools Blocks were ripped off when a rainstorm hit Okinawa at the week-end. 
4. We had a fifteen-minutes break ....

These are examples which classroom teachers [23], have actually condemned as being "clearly unacceptable" with reference to standard practice. It may be noted that the divergent plural forms (underlined) in the premodification are, first, count nouns. Secondly, they are immediately preceded by numerals, which, in a "simple" noun phrase, would make them plural - three days; four engines; two Middle Schools; fifteen minutes, etc. In these examples, however, we are dealing with fixed or idiomatic expressions and not simple noun phrases.

It may also be worth noting the importance of punctuation in this regard. We may distinguish, for example, between a subject noun phrase, a premodifying noun phrase, and a possessive noun phrase: 15 -minute break; 15 minutes' walk. Here are two examples from another formal written source [24]:

i. Harvey Court, the newest addition to the College buildings, lies a few minutes' walk away across the river, and is close to the Arts Faculties and the University Library.

ii. The Cavendish Laboratory is only a short distance away and Cambridge city is within ten minutes' walk.

If we accept these examples then we can say that the form is undoubtedly standard practice. The difference between these examples and those quoted from the Japanese newspapers will not be the number marking of the noun in the premodification but in the punctuation - the use of the hyphen in one and of the apostrophe in the other. But since the change in punctuation, as we have said, will bring about a change in the function of the phrase, the issue may also involve homonymy - i.e., different forms that have the same phonological realization. That is to say, a divergent form such as (a) *ten-minutes walk may be related to the standard forms (b) ten-minute walk or (c) ten minutes' walk, and the difference in punctuation between (a) and (c) may not be realized in speech. In other words, because the pronunciation can be the same, the difference in punctuation may not be realized. Similarly, because the punctuation is the same between (a) and (b) the difference in number marking may not be realized. Thus (a) seems to be a combination of (b) and (c) - the (plural) number marking in (a) agrees with the (plural) number marking in (c), and the punctuation (hyphen) in (a) agrees with the hyphen in (b).

b. proximity

There are cases where the number of the verb only agrees with the number of the immediately preceding noun in defiance of both grammatical and notional concord. This is manifested in 20 out of $386(5 \%)$ examples:

1. ... even the leaves of this kind of onion is sometimes used in the preparation of certain dishes.

2. We feel that part of the explanation for our problems stem from a misunderstanding of our motives.

3. We salute the founding fathers of the EU and the succeeding generation of European leaders whose courage in the face of temptations, adversities and obstacles have carried us thus far.

4. Other projects envisaged for the town is the construction of a Junior Secondary School workshop and school block.

6. The increasing number of independent states in the world call for a new international economic and information order ....

\section{CONCLUSION}

In conclusion, these examples demonstrate what we have been saying about the conflict between the principles underlying concord. In these examples, there seems to be a conflict between grammatical concord and attraction through proximity. The principle of attraction through proximity here, however, does not seem to be reinforced by notional concord, and that is why these examples may seem divergent. The conflict between proximity and grammatical concord which is reflected here, nevertheless, is not uncommon in standard practice. According to Huddleston [19], the choice "is not determined in a purely mechanical way". Of course, no aspect of grammatical analysis or semantic judgement is purely mechanical. What Huddleston seems to be alluding to is the range of choices for which the grammar allows in this area of usage. Obviously, we can identify no underlying principles that will consistently explain concord in these examples other than the conflict between grammatical concord and attraction through proximity. On that basis, we can reasonably conclude that divergence in concord in educated written English in Japan largely reflects the conflict between grammatical concord and concord of proximity, which is not uncommon in this area of standard practice.

What the data has shown is that whereas the rate of divergence is high (in some cases up to 6\%), there are a lot of other high instances of standard American English practice. In most of the texts examined for this study the divergent forms and the standard forms alternate with each other without any apparent contextual determinants. This would appear to underscore inconsistency in handling the complexity and idiosyncrasy of standard practice with respect to concord rather than manifest an "institutionalized" divergent realization of concord.

Because of a desire to elevate divergent grammatical forms into the dignity of national and regional non-native varieties of English, often described as "New Englishes", some writers have focused exclusively on some relatively rare exceptional divergent uses or forms in the English produced by non-native speakers as manifesting characteristic features of "New Englishes". Detailed, descriptive documentation has been lacking. But the most common isolated examples which have often been listed include expressions relating to definite/indefinite distinction (realized by articles); number realization involving noncount nouns; modality, tense and aspect (realized by the verb); concord; and verb + particle (preposition, adverb or prepositional adverb) collocations. In this study, we have examined the incidence of the category of concord in a corpus of educated written English in Japan.

Two issues are of particular interest to us: the stability of the realization of the categories and the statistical likelihood of the occurrence of the divergent forms in particular syntactic and semantic environments; and the distinctiveness or uniqueness of the divergent forms to educated written English in Japan.

Our analysis shows that the divergent ("characteristic") features are not consistently or reliably realized, and that their Standard American English equivalents are used on more than $95 \%$ of occasions of use. Any given deviant form occurs in less than $10 \%$ of instances of use and sometimes alternates with the standard form without any apparent contextual determinant. The divergent forms relating to concord, as 
presented in this study, occur on the average of $4 \%$ of instances of use. So that if we are prepared to label these usage as "a characteristic of Japanese English", then we must inevitably be prepared to justify the overwhelming $96 \%$ of instances of use where the so-called "characteristic" does not or will not occur. What in effect we shall be saying is that the form that occurs in $4 \%$ of instances of use constitutes the "rule" or regular practice in "Japanese English" and the alternative form that occurs in $96 \%$ of instances constitutes "an exception to the rule". Such a position would be ludicrously inconsistent with descriptive linguistics.

The pedagogic notion of "Standard English" does not imply a refusal to accept the existence of (non-native) varieties of English as scholars like Kachru [25] would argue. His suggestion that other varieties of English be recognized would not have been questioned if, as Spencer [26] puts it “... these relatively slight deviations from and extensions of Standard British English are widespread, stable and, above all, locally acceptable. So far, ... impression and opinion has dominated discussion". This is what has been at issue for the past four decades or so.

Some writers have resorted to an attack-to-defend strategy whereby "New Englishes" is being defended not so much by describing such varieties as by attacking the pedagogic notion of "Standard English" or of "correctness". Opposed to the linguistic ethos which suggests that there is a Standard English which must be the accepted educational norm or practice, which some scholars, like Kachru [1], would describe as deficit linguistics, is that which suggests that all forms of English are equal, which scholars like Spencer [26] and Quirk [10] would describe as liberation linguistics. Writers like Quirk [10] still reject the idea of "institutionalized non-native" varieties of English on the basis of "stability", and reiterate (p. 22): "No one would quarrel with any of this provided there was agreement within each such country that it was true, or even that there was a determined policy to make it true. So far as I can see, neither of these conditions obtains, and most of those with authority in education ... in these countries tend to protest that the so-called national variety of English is an attempt to justify inability to acquire what they persist in seeing as 'real' English". Cf. Kachru's reply [25] which goes beyond the specific points made by Quirk to discuss what Kachru identifies as the ideological backdrop to Quirk's concern or position - deficit linguistics.

National consensus apart, there is the grammatical need to address the issue of stability. One way of putting the question will be: "in what sense are these forms 'stable' deviant forms if, as this study has shown, they only occur in less than $10 \%$ of instances of use?" Another way of looking at it could be: "if two forms alternate with each other in the ratio of $90 \%$ to $10 \%$, and there is no apparent contextual determinant, which of them, in terms of frequency, deserves more recognition as the stable form?"

Whether or not we recognize a Japanese Standard variety of English appears to be a socio-political rather than linguistic question. Surely, there is a political or social dimension to the issue, and we are very unlikely to find complete agreement on it. This is one reason why it is all the more important for teacher-trainers, textbook writers and curriculum designers to know what forms they are recognizing and emphasizing as the educational target, which will guide teachers and examiners. Obviously, there can be no purposeful and effective teaching/learning without any required standard. Neither will it be pedagogically useful to have educational standards, which do not reflect social and professional reality. Our analysis shows that whatever we may understand as the "characteristic" features of "Japanese English", as manifested in the Japanese English language quality press, the educated Japanese will be achieving at least $95 \%$ of their "standard" realization if we continue to teach Standard American English in schools and colleges in Japan. If it is a question of "standards", then it may be worth noting that even in the native-speaker setting, such as in the United States of America, the emphasis is always on "standards", and the "marking of grammar" is always the central issue.

\section{REFERENCES}

[1] B. B. Kachru, The Alchemy of English, Oxford: Pergamon, 1986.

[2] H. Coleman, "Is the "false beginner" a false concept?" The Language Teacher, vol. 11, no. 14, pp. 11-17, 1987.

[3] J. D'Angelo, WE-Informed EIL Curriculum at Chukyo: Towards a Functional, Educated, Multilingual Outcome, in Principles and Practices of Teaching English as an International Language (ed. Aya Matsuda), Bristol: Multilingual Matters, 2012.

[4] J. D'Angelo, "Japanese English: Refocusing the discussion," Paper delivered as part of panel on 'The Possibility of Japanese English', $26^{\text {th }}$ JAFAE, Kobe, July 3, 2010.

[5] S. Ike, Japanese English as a Variety, Phd Thesis, University of Melbourne, 2010.

[6] K. Bolton, Chinese Englishes: A Sociolinguistic History, Cambridge: Cambridge University Press, 2003.

[7] J. A. Stanlaw, Japanese English: Language and Culture Contact. Hong Kong: Hong Kong University Press, 2004.

[8] R. H. Quirk, S. Greenbaum, G. Leech, and Svartvik, A Comprehensive Grammar of the English Language, London: Longman, Jan. 1985.

[9] J. R. Milroy and L. Milroy, Authority in Language, New York: Routledge \& Kegan Paul, 1987.

[10] R. Quirk, "Language Varieties and Standard Language," JALT Journal, vol. 2 , no. 1, pp. 14-25, 1989.

[11] J. Tregidgo and S. Philip, Practical English Usage for Overseas Students, London: Longman, 1962.

[12] L. Todd and I. Hancock, International English Usage, Kent: Groom Helm, 1986.

[13] J. Williams, "Non-native varieties of English: A special case of language acquisition," English World-Wide, vol. 8, pp. 161-199, 1987.

[14] L. Selinker, "Interlanguage," International Review of Applied Linguistics, vol. 10, pp. 209-230, 1972.

[15] D. Bickerton, "Pidginization and creolization: Language acquisition and language universals," in Pidgin and Creole Linguistics, A. Valdman, Ed., Bloomington: Indiana University Press, 1977.

[16] D. Bolinger, Aspects of Language, London: Harcourt B. Jovanovich, 1981.

[17] B. Magura, "South African black English," World Englishes, vol. 4, no. 2, pp. 251-256, 1985.

[18] D. Crystal, Rediscover Grammar with David Crystal, Harlow: Longman, 1988.

[19] R. Huddleston, English Grammar: An Outline, Cambridge: CUP, 1988.

[20] N. Burton-Roberts, Analyzing Sentences, Essex: Longman, 1986.

[21] New Zealand and Sunday Times, "Radio NZ banned 'sexist' words," June, 5, 1988.

[22] Collins Cobuild Advanced Dictionary, HarperCollins, UK. $9^{\text {th }}$ Edition, 2018.

[23] C. Tingley, "Deviance in the English of Ghanaian newspapers," in English World-Wide, M. Gorlach, Ed., vol. 2, no. 1, pp. 39-62, 1981.

[24] Graduate Studies Prospectus 1989-1990, University of Cambridge, vol. 119, pp. 108.

[25] B. B. Kachru, Asian Englishes: Beyond the Canon, Hong Kong: Hong Kong University Press, 2005.

[26] J. Spencer, The English Language in West Africa, pp. 22-144. London: Longman, 1973. 


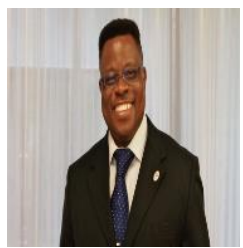

Kolawole Olagboyega is a professor of English and Applied Linguistics at the Department of English, Tsuru University, Japan. He was the director of the English programs and the director of the Language Acquisition Center at the International College of Liberal Arts, Yamanashi Gakuin University, Japan.

$\mathrm{He}$ is an alumnus of four universities including, the University of Sheffield (Ph.D. in English and applied linguistics), University of Cambridge (MPhil. in English and applied linguistics), University of Greenwich (PGCE in post-compulsory education and training), - all the in United Kingdom, and Obafemi Awolowo University, Nigeria (B.A.Ed. First Class Honors in English/education.). He is an accomplished scholar and has published widely in the area of applied linguistics and language teaching with many publications in international journals. He is a fellow of the Cambridge Commonwealth Society.

Prof. Olagboyega has taught a variety of students at both the undergraduate and graduate levels in Nigeria, the United Kingdom, Oman, North Cyprus and Japan. 